\title{
Seeing and Being Seen: The Multimodality of Museum Spectatorship
}

\author{
*Dimitra Christidou, The Nordic Centre of Heritage Learning and Creativity \\ **Sophia Diamantopoulou, University College London (UCL)
}

\begin{abstract}
This article argues that museum visiting and the act of 'spectatorship', both of which are often assumed to be ocularcentric, are multimodal events. Anchored in Goffman's dramaturgy and frame analysis theory, as well as Kress's multimodal and social semiotic theory of representation and communication, this article presents an apposite interpretative and methodological framework to account for what has not been widely addressed by museum studies; that is, the multimodality of the museum experience. By drawing upon audio-visual excerpts of museum encounters, this analysis brings to the fore the embodied visiting and viewing practices of visitors in museum galleries. Specifically, this article highlights the range of modes of communication and representation, beyond gazing and looking, which are employed, negotiated and regulated within the social context of the visit. The article suggests that visitors' experiences are embodied and performative interactions with the exhibits and other visitors.
\end{abstract}

Key words: embodiment, multimodality, museums, social interaction, visitors

\section{Introduction}

Research on the dimensions of the museum experience has adopted perception-oriented perspectives focused mostly on individual visitors and their flow (Bitgood 2006, 2014; Yalowitz and Bronnenkant 2009) or talk in response to an exhibit or one of its aspects (Allen 2002; Leinhardt et al. 2002; Pierroux 2003; Leinhardt and Knutson 2004; Knutson and Crowley 2010; Roppola 2013). Most scholars have treated talk as the primary medium through which visitors articulate their visual perception and cognition. Recently, due to a growing interest in situated learning, collaborative action and the omnipresence of digital and hands-on exhibits, several researchers have explored alternative modes of engagement with the exhibits, such as movement, gaze and pointing (Diamantopoulou 2008a, 2008b; Diamantopoulou and Kress 2010; Christidou 2012, 2013, in press; vom Lehn 2002; 2008; Lindstrand 2008; Insulander 2010). Despite this shift in interest, the need remains for further investigation into the ways in which visitors collaboratively encounter and engage with the exhibits and each other while in museums. Research into this area needs to consider combining visitors' verbal responses with their actual physical engagement and interaction with each other and the exhibits (Pattison and Dierking 2013; Davies and Heath 2014). What follows contributes towards discussions in this emerging area.

This article critically engages with the concept of 'spectatorship' and does so with the aim of avoiding any implicit assumption that spectatorship is a matter of viewing by static and isolated human subjects. It is partly that studying museums, and their exhibits, alerts us to the 'embodied experiences' of visitors who gaze, walk and talk as they chart their way through an exhibition (Leahy 2012; Roppola 2013).It is also that they may do this in concert with others with whom they arrive and may enlist as co-visitors in the course of their visit. Drawing upon two audio-visual excerpts, this article supports the argument that museum spectatorship is a multimodal performance, entailing a series of embodied performances, such as entering galleries, scanning, perusing, walking, talking, photographing and pointing at exhibits and labels.

Museum \& Society, March 2016. 14 (1) 12-32 @ 2016, Dimitra Christidou, SophiaDiamantopoulou. ISSN 1479-8360 
The analysis draws upon methodological developments within sociology and in particular Erving Goffman's dramaturgy and frame analysis theory (1963; 1971), as well as Gunther Kress's (2010) multimodal and social semiotic theory of representation and communication. By drawing upon multimodality, we show how talk, gesture, gaze and elements of the material context blend together and contribute to the production of meaning. We expand on existing sociocultural research into museums, stressing that museum encounters are embodied and multimodal events, during which physical movement, gesture, and gaze may reveal aspects of meaning making not apparent through analysis of the verbal mode alone. By treating nonverbal modes of expression as resources of meaning-making activity, we suggest that action, experience and communication may be brought into fruitful dialogue, if not integrated, to foreground the multiplicity of ways through which people communicate (Bezemer and Mavers 2011).

It is through bringing together these two theories, ethnomethodology and multimodal social semiotics that we engage in a much needed interdisciplinary conversation (Dicks 2014). The virtue of these perspectives is that, by contrast to structural and deterministic sociological approaches, they permit us to theorize the agency of visitors as co-producers of meaning. The article proposes an appropriate interpretative and methodological framework which illuminates the social worlds of museums. Both the theoretical framework and the methodological tools employed allow the traditional mind-body dualism to be overcome in order to explore the modes and performances of visitors' encounters, as they arise in and through interaction with people and exhibits. The approach adopted in this article allows us to better understand this mediation through the exhibits, as well as through other fellow and co-present visitors. By raising social interaction to prominence, this article (i) foregrounds the social worlds of museums; and (ii) challenges notions of the 'static' visitor and of the 'ocularcentric' museum experience attending to the visitors' role (agency) in the negotiation and shaping of their meaning-making. First, the article discusses the dominance of vision as an essential characteristic of the museum experience, which positions visitors both as spectators and spectacles. It then foregrounds the interrelation between visitors and the emerging context of their encounters, following their actions and inactions moment by moment. Lastly, the article details the methodological framework informing data collection and analysis of the two fragments of visitors' encounters at two museums in London, UK.

\section{Seeing and being seen}

Although embodied experiences are what museums and exhibits offer as their very essence (Roppola 2013), McClellan argues that (2003: 36) 'encouraging visitors to look and see has long been recognized as the principal task of the mainstream art museum'. Indeed, visitors are often referred to as viewers or 'discursive viewers' (Deeth 2012: 12), prompting several researchers to differentiate between 'looking in everyday life' and 'gazing in museums' (O'Neill and Dufresne-Tassé 1997; Illeris 2006). The sense of vision is further foregrounded in the dominant discourse of exhibition marketing materials with visitors being invited to 'see' the exhibition and 'look at' the exhibits (Dudley 2012), as well as in educational programmes and resources which ask visitors either to locate artworks or re-create images of these artworks [i.e. Visual Thinking Strategies (VTS)]. Museums are thus constructed as 'a space of observation' (Bennett 1994:24) with visitors relying heavily on their vision and the interpretation of museums, while performing subtle shifts between gazing and glancing, prolonged silence and queuing in front of popular exhibits (O'Neill and Dufresne-Tassé 1997; Dudley 2012).

Throughout this article, we use the term 'spectatorship' as a key metaphor in describing the duality of the visitor as both the spectator and the spectacle. Museum spectatorship is often assumed to unfold in polite, distant contemplation and hushed reverence, with visitors performing carefully designed and socially negotiated routines with regard to 'route, speed, gestures, speaking, and sound' (Borden 2001: 184). These performances are coupled with several 'involvement shields' (Goffman 1963: 38) - that is, adopting several modes, so as to avoid or limit social exchanges with those sharing the same gallery space. As museum galleries are public spaces where visitors come along with friends or family and meet several others (vom Lehn 2002, 2013; Christidou 2012; 2013; in press), museum spectatorship is further shaped by this social context and the co-presence of other visitors. It is thus expected 
that all actions and inactions trigger some sort of response from all those who happen to be in the same perceptual range (Goffman 1981; vom Lehn 2013; Christidou 2015) with some researchers suggesting that the visitor's gaze may be disrupted by the presence of others (vom Lehn and Heath 2007). By drawing upon a range of modes of communication visitors orchestrate their embodied attempt to convey their willingness to either be included in, or excluded from a given interaction (Christidou 2015). As proximity, distance and pace are part of the mode of movement, the importance of this mode rises to prominence.

\section{Seeing and being seen through movement}

Museums are storytellers, curating a storyline through their collections, the exhibits, the interpretive resources, as well as through the space, design and architecture of the building (Bennett 1995; MacLeod et al. 2012). According to Tzortzi (2014: 328), 'the organisation of movement is a concept inherent in museum design' and thus, a part of the curated storyline. This means that the bodily engagements unfolding within the museum space are part of the narrative of the museum, reflecting the duality of the museum in setting both 'the stage' and 'the script' (Duncan 1995: 12).

Accompanied by specific rules, which are very strict at certain institutions, movement in museums consists of 'knowing how and where to stand, [and] where and how fast to walk' (Leahy 2012: 5). Moreover, Leahy (2012: 75) argues that 'walking choreographs visuality within the museum' and thus, spectatorship. Walking, which is part of the mode of movement, has been linked to visuality and engagement and, thus, used to determine the 'attracting' and 'holding' power of an exhibit and the effectiveness of the exhibition design in engaging visitors' attention (Bitgood 2006, 2014; Yalowitz and Bronnenkant 2009). Recent research suggests that movement affects the order in which the exhibits are seen (Leahy 2012) and the ways in which these are experienced (vom Lehn 2013; Christidou 2015).

The shifting from one exhibit to another, the on-going selection of resources and loci of attention, along with the regulation of movement allow museum encounters to be treated as an 'on-going choreography' (Diamantopoulou and Christidou in press) during which visitors are both the choreographers and the performers, 'actively [creating] the contexts in which they experience particular exhibits' (vom Lehn et al. 2001: 207).

Movement is a key element in the experience of spectatorship for which it is also an anchor. The visitor is the mobile spectator, 'seeing' the 'spectacle' from different viewpoints, angles, distances and so forth. Movement becomes an essential part of 'seeing' the exhibits and a mode through which the visitors 'see' the exhibition (Diamantopoulou and Kress 2010) while 'being seen' by other visitors who happen to be in the same place at the same time.

The multimodality of spectatorship does not only affect the overall pace and the experience of the immediate participants, but also the pace and experience of those who just happen to share the same space (Christidou 2015). Additionally, visitors use language, body signals (i.e. gesturing, pointing, waving) and actions (i.e. moving faster or slower, standing still) in order to establish themselves as a social entity, choreographing and orchestrating their common movement in space. Their awareness of where the other co-visitors are (Christidou 2015) affects, if not determines, the coordination of the movement, choices and actions of their companion(s), as well as those of the other visitors in the gallery space. Therefore, there seems to exist an inherent social dimension in the ways visitors move through the gallery space.

The need to engage with the concept of spectatorship through a multimodal perspective becomes all the more necessary, if we take account of research which suggests that speech, movement and gestures often ratify what has already been manifested in the mode of vision (Diamantopoulou and Kress forthcoming). Bodily movement, perception and the aesthetic experience are interlinked and informed by the museum script while being further negotiated and regulated through the on-going social interaction unfolding on the museum floor. However, as vom Lehn and colleagues (2002: 16) argue, the social organization of bodies in space has to a large extent been ignored, and researchers have instead concentrated on the organization of social interaction through language. Engaging with spectatorship in a multimodal framework resonates with the above arguments for reinstating the multimodal dimensions of social interaction. 


\section{Visitors' dance of agency}

Agency entails the ability to assign relevance and significance to things and events (Duranti 2004). Visitors perform agency through their ongoing decisions and selections while in the galleries, which involve mediational means such as language and action (Diamantopoulou et al. 2012). This article argues that visitors demonstrate agency through their orchestration of all modes that are employed in their engagement with the exhibit and the social space of the exhibition (gazing, pointing gestures, body movement, speech and so forth). Understanding visitors' agency involves not only exploring the themes of their conversations (Leinhardt et al. 2002; Leinhardt and Knutson 2004), but also the ways they say what they say; how their actions are jointly linked, negotiated, occasioned and deployed (Rowe 2002). Our work offers an understanding of how the agency of the visitors is instantiated as they 'orchestrate' the different modes they have available for engagement with the exhibits and other visitors, while they move around the museum galleries. Despite the fact that visitors' movement informs the design of exhibitions and vice versa, the role of visitors' agency in shaping their experience through movement has not been seen as key in previous research.

Based on our work, we argue that while moving in the galleries, visitors encounter people and exhibits, and they materially realize through embodiment aspects of their visiting experience and their agency. Through their ongoing movement and shifting between different modalities, visitors seem, as if they are dancing while performing their spectatorship, which is often so gracefully performed that it seems like a choreographed 'dance of agency' (Pickering 1995: 21-22) alongside the 'acrobatics' of their 'collaboration' (Ingold 2011: 92). At the same time, by introducing the concept of agency and by suggesting that visitors actually stage a choreographed performance, we try to flag up the paradox that, although both visitors and curators assume that people come to 'see', they actually do a lot more than that. Visitors act upon the performance by staging their own, one which is prompted by gaze and delivered by movement. This is what we refer to as their own agentive engagement.

The article claims that visitors move through the galleries as agents of their own experience: they engage with the social world as agents who view, perform and choreograph their embodied multimodal experience in the museum. The metaphors of dance and choreography illustrate the connection of multimodal engagement with the social world (Kress 2010) and the dramaturgical and performative aspect of spectatorship (Goffman 1963).

\section{Theoretical and Methodological Approach}

The methodological approach and theoretical framework employed draw upon analytic developments in the social sciences, in particular Goffman's (1963; 1971) symbolic interactionist studies of behaviour in public places, ethnomethodology (Garfinkel 1967), conversation analysis (CA) and Kress's (2010) multimodal and social semiotic theory of representation and communication. Taken together these four paradigms contribute both to an understanding of experience as 'situated in embodied practice and movement' (Pink 2010: 332) and to our knowledge of human social action as an amalgam of talk, bodily conduct and other modes of communication. However, taken separately, each paradigm provides a distinctive way of exploring, approaching and knowing the social world and everyday interaction.

Specifically, Goffman's work (1963; 1971) inspires us to view museum galleries as stages where visitors 'perform themselves', much like actors performing on a stage for their audience. Goffman's work informs the methodological and analytical framework in terms of the multiple roles that a person may enact under specific circumstances and within specific contexts of interaction. Again specifically, the constant alterations of roles adopted by the visitors reveal the social dynamics of the museum encounters. Moreover, Goffman's work sheds light on the organization of body movement, exploring its contribution to the order of interaction.

We then turn to ethnomethodology (EM) and conversation analysis (CA) - a research tradition that grew out of ethnomethodology - as they both offer insights regarding the fine details of the order that governs everyday interactions, especially those related to language use. By coupling EM and CA with Goffman, we focus on action during everyday interactions in terms of how that action is coordinated with and through other actions, talk and material objects, thereby highlighting the indexical or situated character of social action (Garfinkel 1967). 
As we are interested in exploring social action, we have to account for observable verbal and embodied conduct and that is why we turn to the multimodal social semiotic theory of representation and communication (Kress 2010; Diamantopoulou 2008b). Moreover, this theoretical perspective allows us to treat communication as a response to a prompt, with which individuals engage, driven by their interests. According to this theory, visitors select aspects of the material world to attend to, and thus transform the resources that were initially made available to them.

Informed by Kress's standpoint that communication is a response to a prompt, we argue that visitors are driven by their interest and context specific stimuli to make constant selections of representational and communicational resources. In order to make these selections, visitors employ a range of modes such as speech, gaze, gesture and movement. The semiotic work performed by each mode employed does not work in isolation, but in collaboration with other modes, which are prevalent in different degrees. The meanings realized in one mode, such as speech, may resonate with those expressed in another, such as movement, or could even be contradictory, such as when gaze suggests a different engagement to that realized in speech. Whatever the dynamic of modes within this multimodal ensemble, visitors as agents in this meaning making process make their own selections, shifting between the modes they perform. The interconnection of modes, as well as the ongoing selection of and shifting between modes resemble a 'choreography' (Diamantopoulou and Christidou in press), during which visitors carefully 'orchestrate' several modes (Kress 2010: 197).

The focus of our analysis is on the ongoing interaction between different modes when visitors spend time in galleries. The analysis centres on the sequential and indexical character of participants' conduct and the ways in which they simultaneously view the exhibits as spectators and become spectacles for other visitors - both along with those they happen to be with and others who just happen to be in the 'same space'. Additionally, our analysis highlights the inextricable link between action and context. The moment-by-moment social interactions that take place during gallery visits are emergent and contingently accomplished with regard to what preceded and what succeeded (Heritage 1984). Thus, the methodological and interpretative tools proposed are apt for investigating in situ processes of visitors' making of meaning by attending to their micro-movement, rather than relying on subsequent purely linguistic recounts of this experience by interviewing the visitors, or resorting to measurements of learning, as indicators of the viewing experience.

This article draws upon two sets of audio-visual data collected for two projects, both conducted partially or entirely in the UK between 2007 and 2012. Pairs or groups of visitors were audio and videotaped while in two museums in London, UK: the Museum of London and the Wellcome Collection. Visitors at the Museum of London consented in writing to being tracked and filmed by the researcher during their visit for research and publication purposes. The data collection was oriented towards documenting the multimodality of movement and gaze, and as a result less emphasis was placed on speech. At the Wellcome Collection, visitors gave their consent implicitly, based on 'their behaviour in a situation of choice' (Gutwill 2002: 232), that is, to enter or not the exhibition area where the research is taking place.

The examples in this article include selections from multimodal transcripts employing specific transcribing conventions. The emphasis here is not on the presentation of the transcription method informed by our analytical and interpretative framework, but on the actual framework itself and its potential to inform an approach for conducting observations and analyses of videos. The excerpts showcase the application of the theory and provide the entry point into the theoretical discussion. This approach attends to the significance of each mode involved in the museum spectatorship separately and, subsequently, on the possibilities arising from the orchestration of these modes by the visitors as agents in shaping their visiting experience.

\section{Performing museum spectatorship}

The following two encounters attend to two different 'frames' within which visitors perform while 'seeing and being seen' in museum galleries. The first frame, holding the ground for engagement, showcases visitors setting the stage by configuring the space through which other social agents will engage with their multimodal performances. The second frame, negotiating 
co-presence on the museum floor, shifts the attention to the modes in which visitors negotiate and communicate their ongoing experiences when encountering other social agents who are not ratified as active participants in the visitors' interactions.

\section{Holding the ground for engagement}

The first example unfolds in the London before London gallery at the Museum of London, and involves a pair of young female adults, referred to as W1 and W2. The analysis of this excerpt is led by the underpinning assumption of Kress's multimodal and social semiotic theory of representation and communication, according to which every instance of semiotic action through speech, movement, gaze or other mode is meaningful and significant. Kress's work is used to showcase the multimodal performance of the participants, which develops in their interaction with each other, the exhibition design, and the other visitors present, as they prepare the ground and subsequently hold the ground for the engagement of their companion. The visit of these two participants exemplifies a range of possibilities for holding the ground and framing their joint experiences through a range of embodied modes employed, such as gaze, movement, pointing gestures and speech. The example additionally illustrates the interchanging of roles performed within the gallery, as the two visitors take turns in leading and shaping each other's engagement.

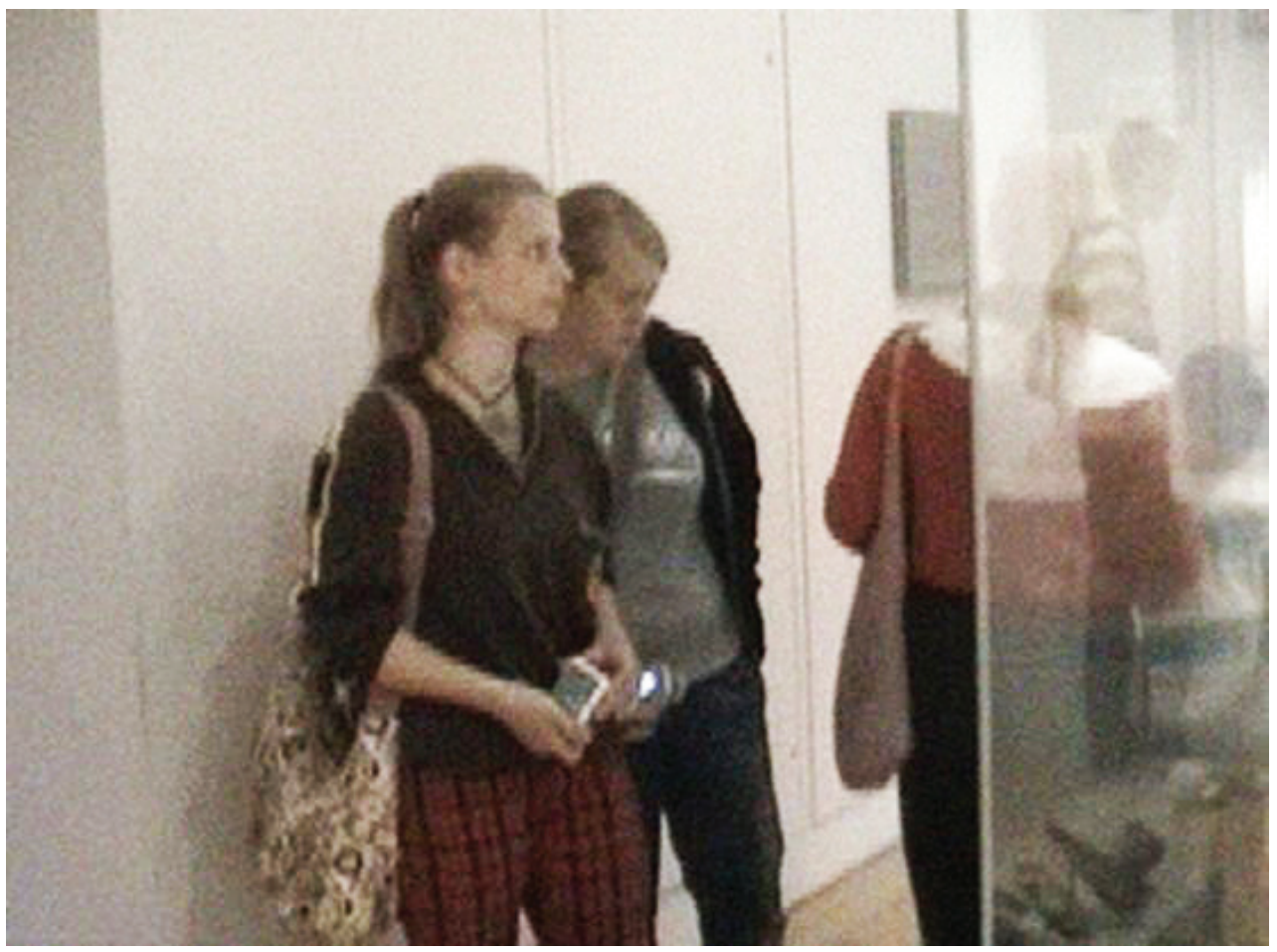

Figure 1

The video excerpt of a few seconds starts with W1 and W2 pacing down the narrow corridor by the entrance to the exhibition (Figure 1), scanning through the exhibits in the glass case, without talking. W2 is framing W1 from the left, being positioned slightly behind her. Both have their torsos and heads steadily rotated to the left, while scanning the display case with their gaze. Their movement and placement in space demonstrates coordination, identical pacing, steady distance between them, a parallel alignment of their bodies and a simultaneous, synchronous 


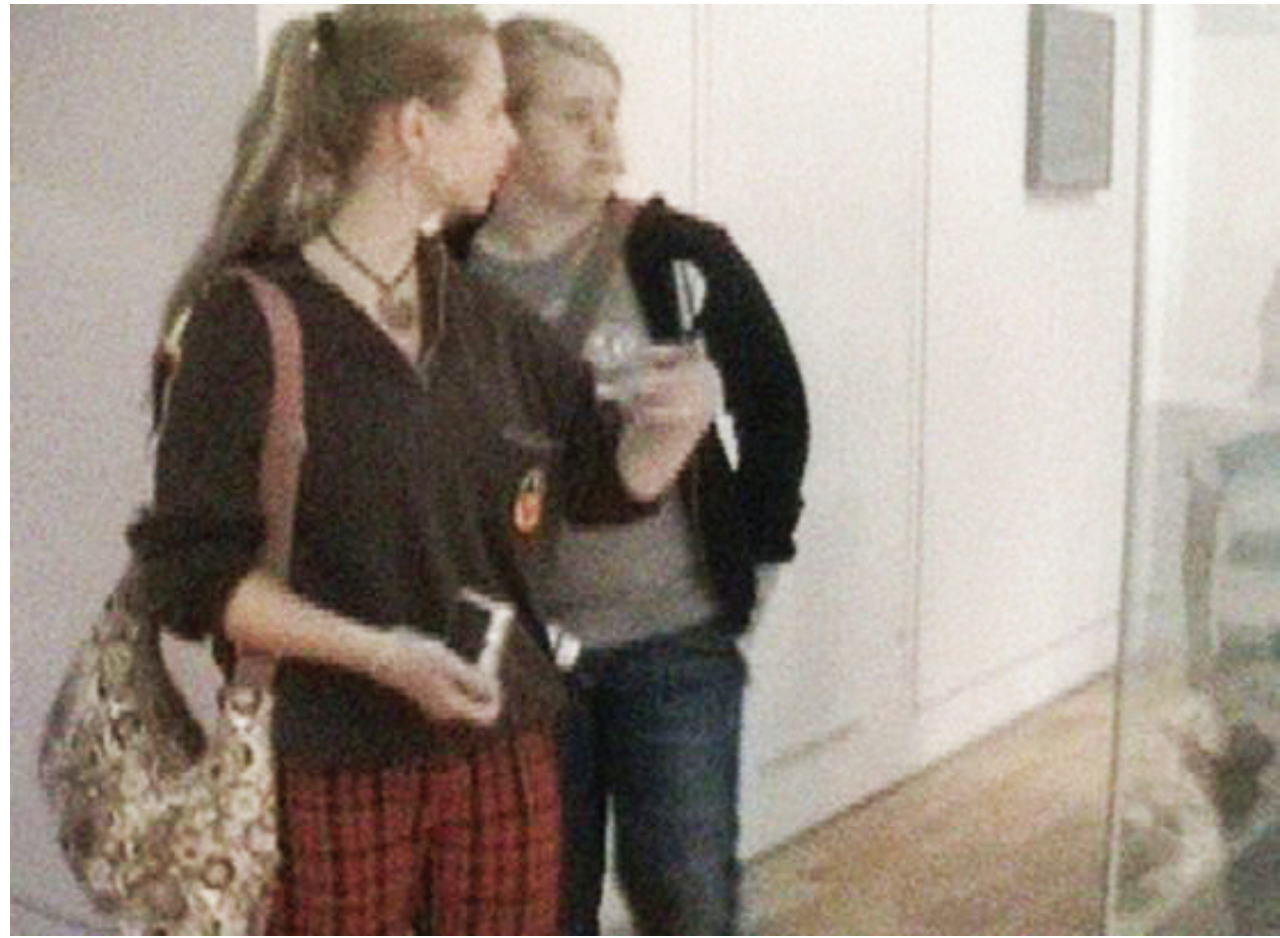

Figure 2

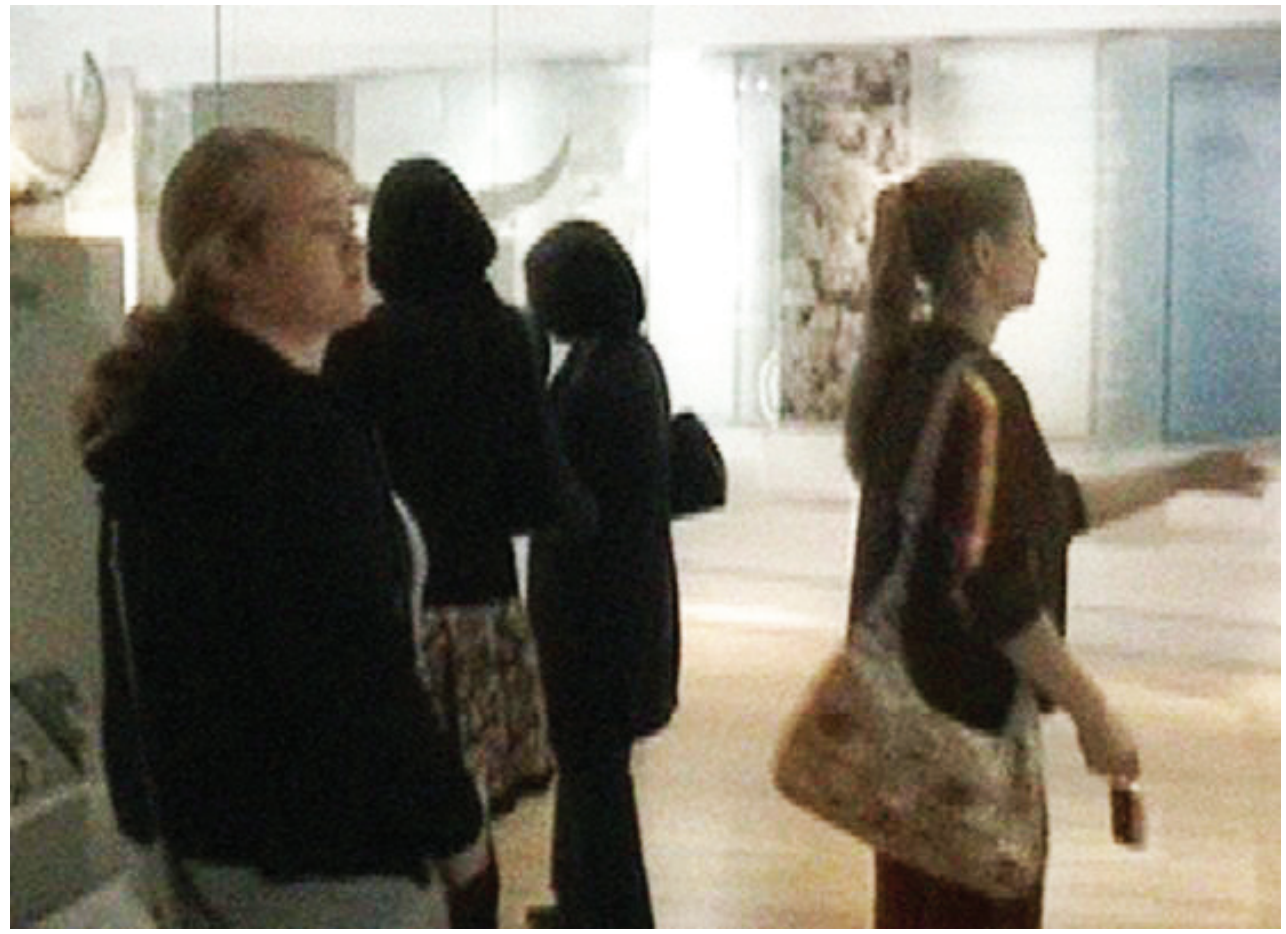

Figure 3 


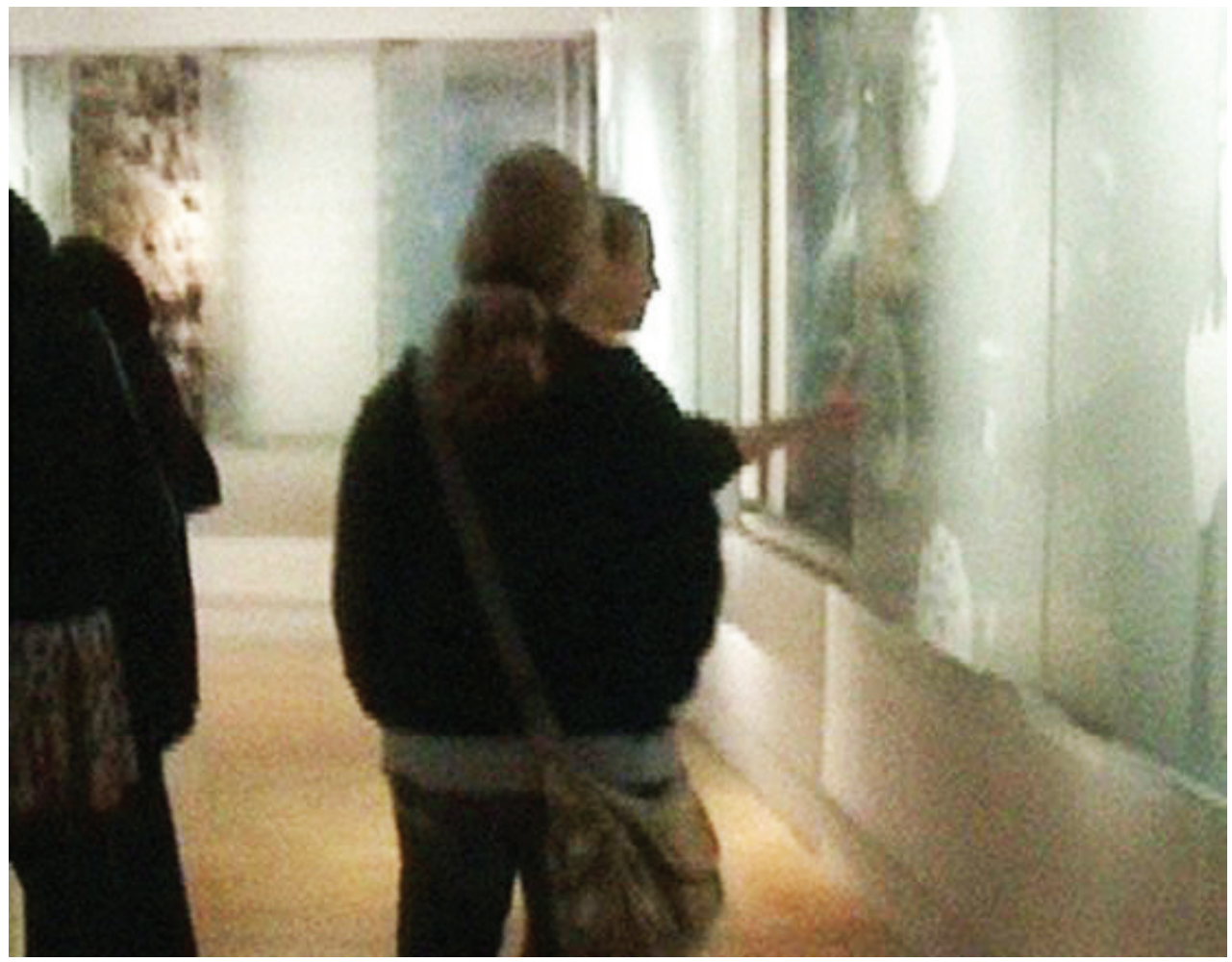

Figure 4

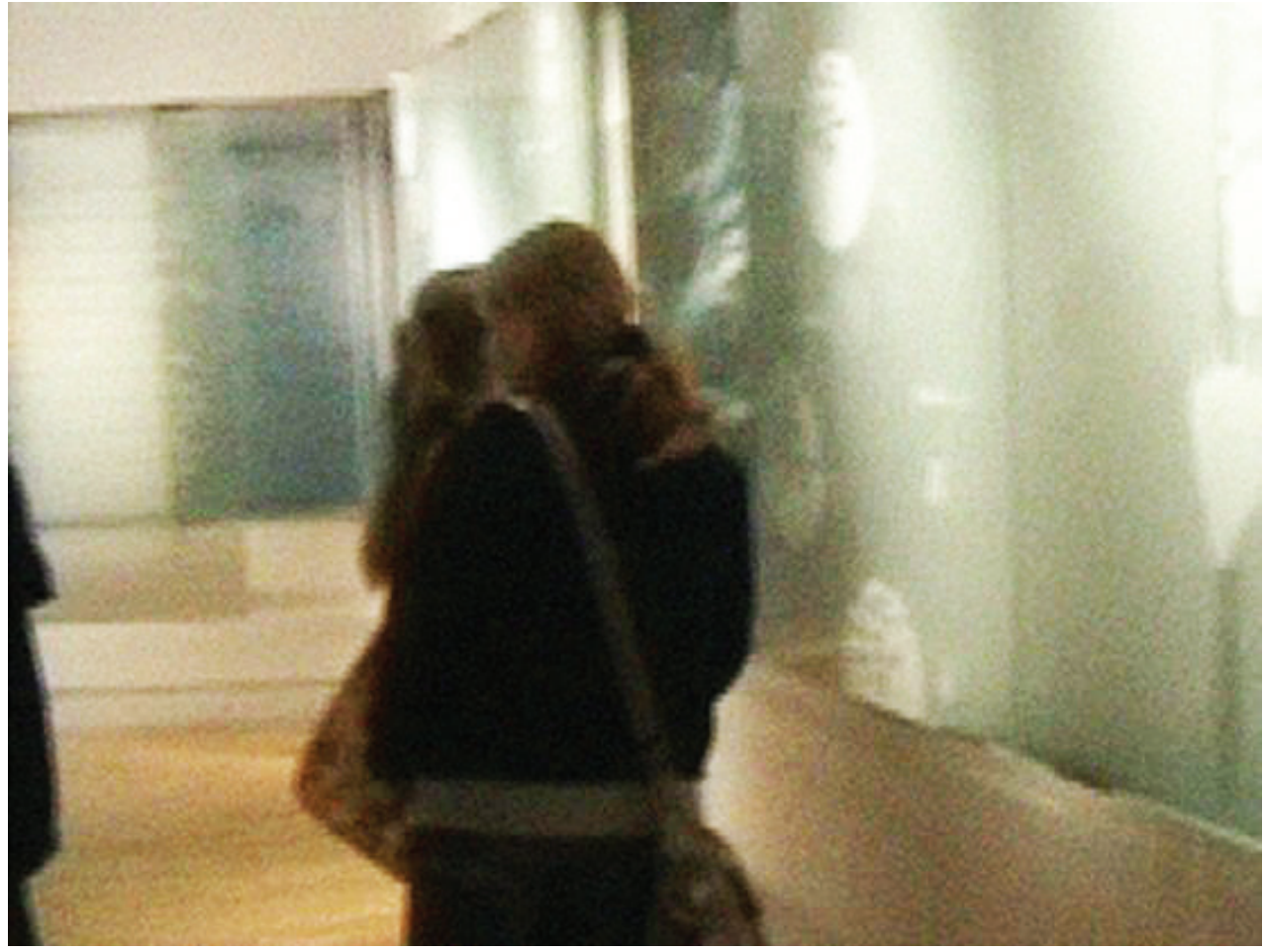

Figure 5 
movement of their legs as they walk. Such movement can potentially be a significant marker of their intentions and of their interest not to dwell for long in this initial part of the exhibition.

As they approach the end of the long glass case, W1 briefly stops, raises her hand to point towards the end of the corridor and slightly turns her head towards W2, without meeting her gaze (Figure 2). Through an orchestration of four modes - movement, pointing gestures, gaze and speech - W1 takes the lead in negotiating their path in space. The performative act of seeking consent from her companion, in order to jointly devise their navigation plan, is materialized through a multiplicity of modes - movement, pointing gestures and gaze - which precede the mode of speech that finally ratifies what has already been expressed by the other modes.

W1 is then seen walking slowly in front, with W2 following behind and to W1's right, their torsos and heads turned to the right towards a long glass wall panel. The gaze of W1 is caught by a specific exhibit as she leisurely scans the panel, when she immediately performs a sharp rotation of her whole body, twisting her torso and turning her head further to catch sight of W2's gaze, to signal that she has come across something interesting (Figure 3). W2 acknowledges the change in W1's movement, the rotation of her body axis, head and gaze, through a slight and very brief shift in gaze, and continues reading the part of the panel she was initially engaged in reading.

Despite minimal acknowledgement and a lack of response by W2, W1 turns towards the panel, while performing a deictic movement (Figure 4) pointing to the part of the panel that interests her, keeping her gaze fixed on the point. It is the movement of her arm, which, as it swings upwards, leads the rotation of her torso and head towards the part of the panel that initially attracted W1's attention and prompted her to frame this for W2. The movement of W1, along with her succeeding performances, indicate her intention to share the panel information and her views with W2. Specifically, W1's slight rotational movement enables her to position herself frontally before the exhibit, standing with her palms open, towards the exhibit's panel.

By orchestrating a range of modes $\mathrm{W} 1$ holds the ground, embodying her invitation to W2 to join her in her encounter, a performance that successfully attracts W2's attention and attendance as she moves forward and rotates her body to the left, positioning herself at an angle in order to view both the panel and W1. The full alignment of legs, torso, head and gaze and turn of W2 towards both W1 and the exhibit are indicative of the full attention which W2 has given to the performative space of W1. Upon joining her, W1 uses a deictic and sweeping movement of her hand so as to point out aspects of the exhibit.

While exploring the exhibit together, W2's attention is drawn by a movement behind. Another pair of visitors, who had briefly approached W1 and W2 as they were paying attention to a specific exhibit on the opposite wall, now move apart, creating an empty space. The response to this prompt is manifest in W2's slow and soft turn of the head (Figure 5), slow rotation of the upper torso, slight leaning forward and lowering of the gaze and head over her left shoulder where one of the other visitors has remained. W2 then briefly resumes her previous position, turning towards $\mathrm{W} 1$ to invite her now to attend to the exhibit behind them. Through this turn W2 signals the end for the performance of W1 by not paying attention to her any longer. W1's gaze remains fixed on the text of the panel, and with an additional sweeping movement of the hand towards the panel, invites W2 to engage with the text further.

W2 remains rotated and through a slight shift of her head and gazing back towards W1, invites her to the part of the exhibition which she has now chosen to frame for them. They both rotate towards each other and stand in line, positioning their bodies behind another visitor, while reaching out with their gaze towards the exhibit from a distance (Figure 6), as W1 points towards it.

W2 now takes the lead and initiates movement towards the new exhibit. She is quickly followed by W1 and they both fit into the narrow space right next to the other visitor (Figure 7). W2 selects this opportunity to move into the space that had previously been salient in her experience, as she notices the two other female visitors gathering there in a frontal arrangement of all body parts, a sign of full engagement. Once W2 manages to stand in front of this new exhibit, she takes the opportunity to hold the space for W1's further engagement with it. W1 steps slightly back and stands turned to both W2 and the exhibit. Observing the performance of W1, she leans forward (Figure 8) to observe details and read the labels. The posture of 


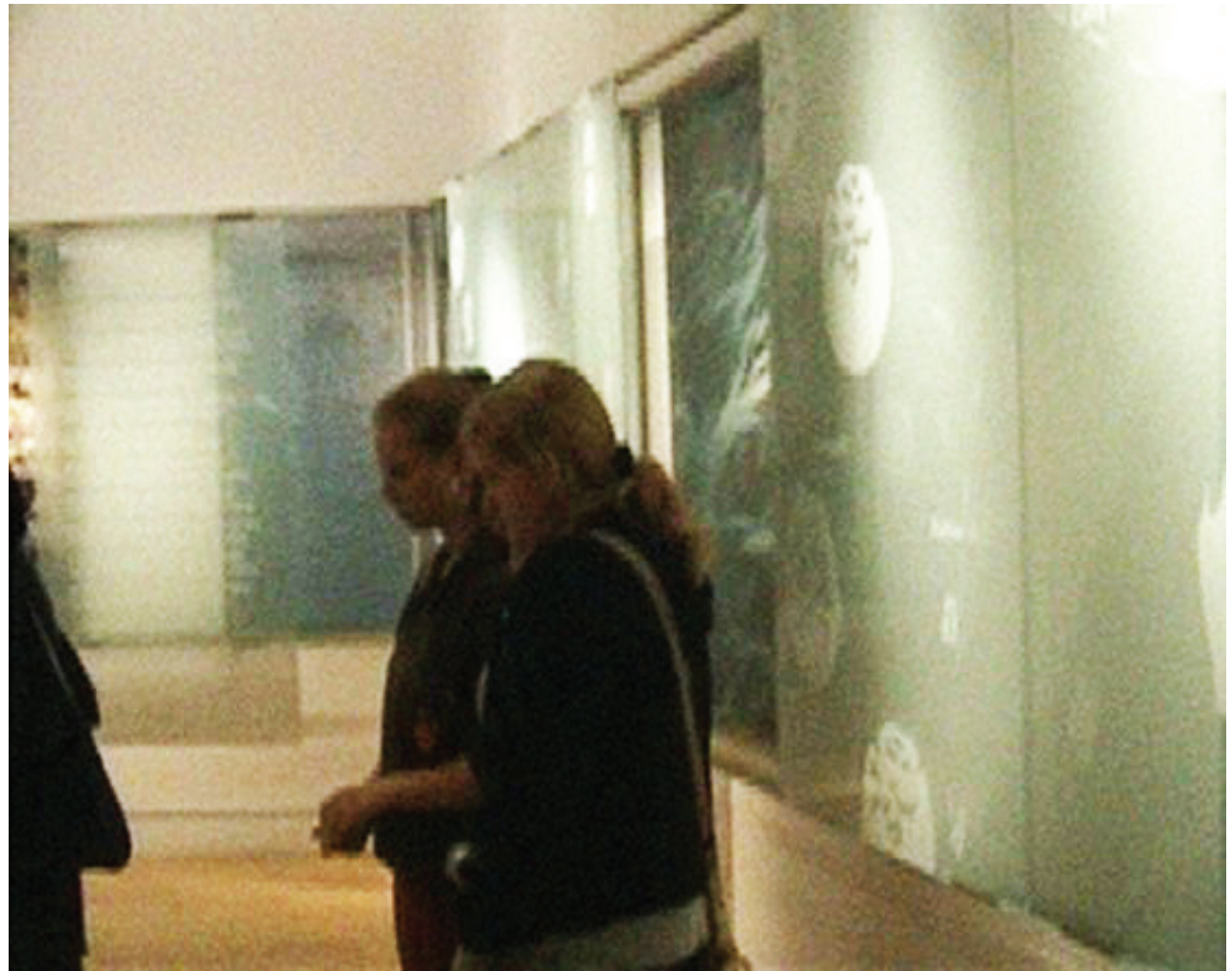

Figure 6

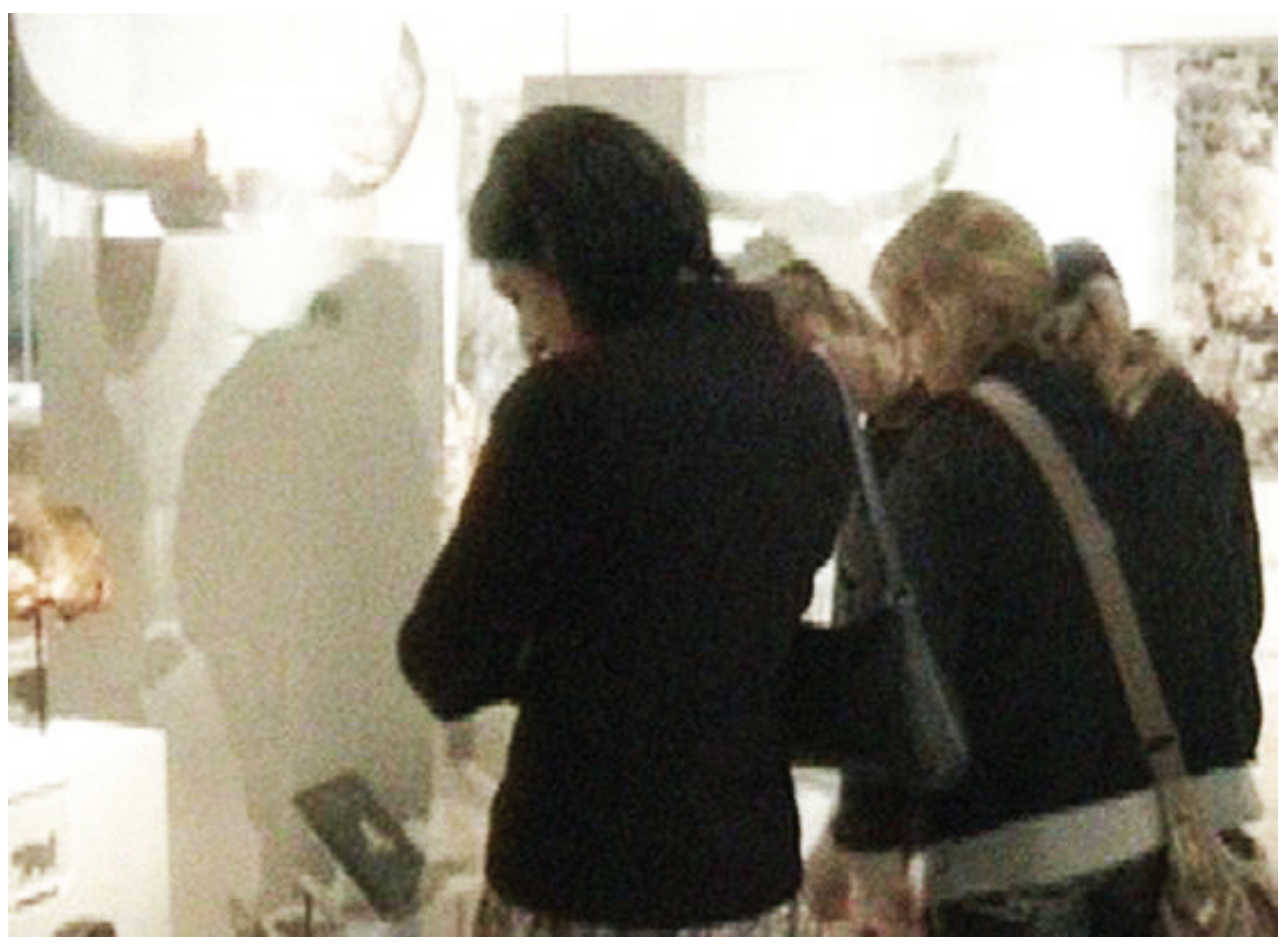

Figure 7 


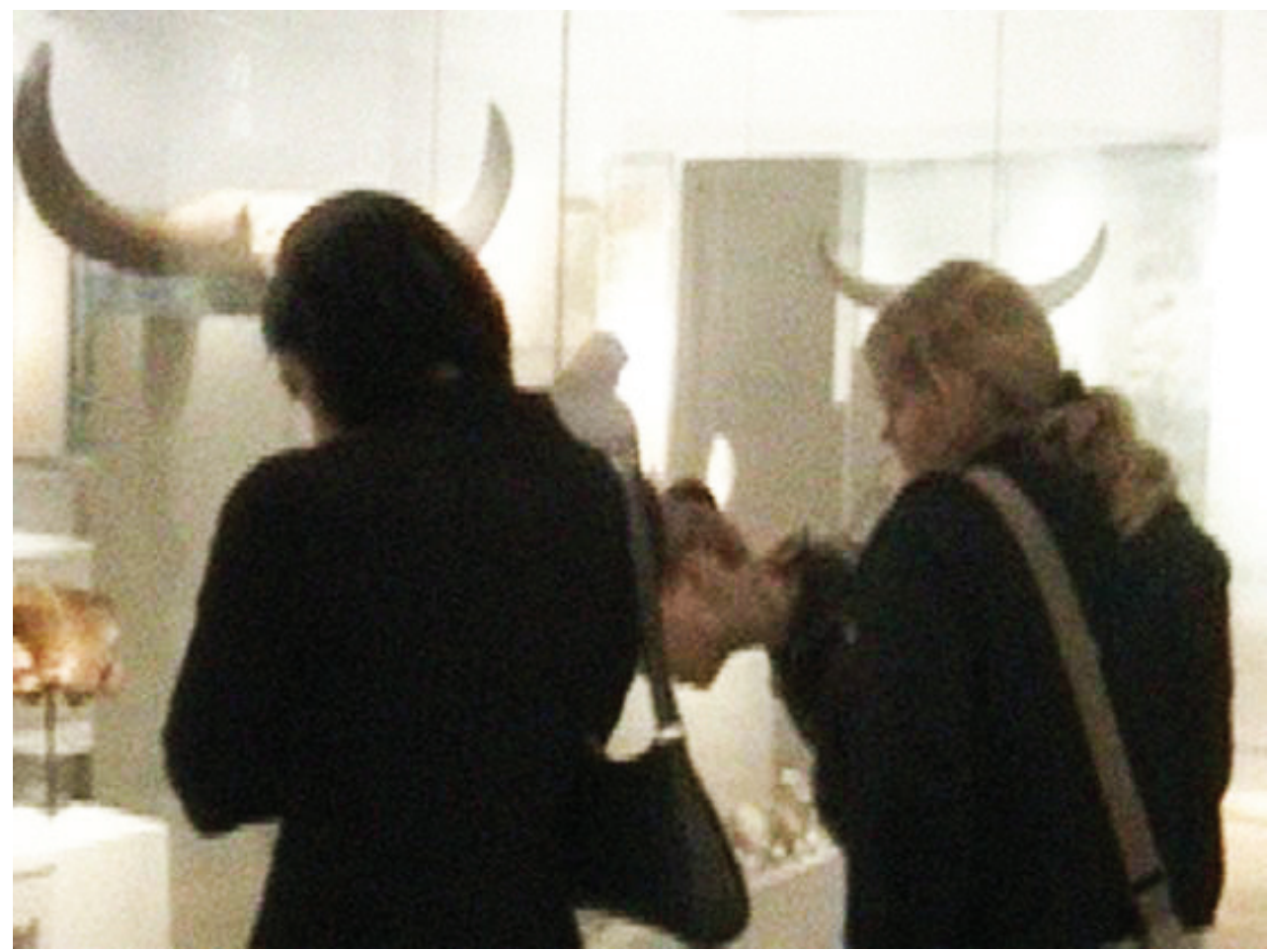

Figure 8

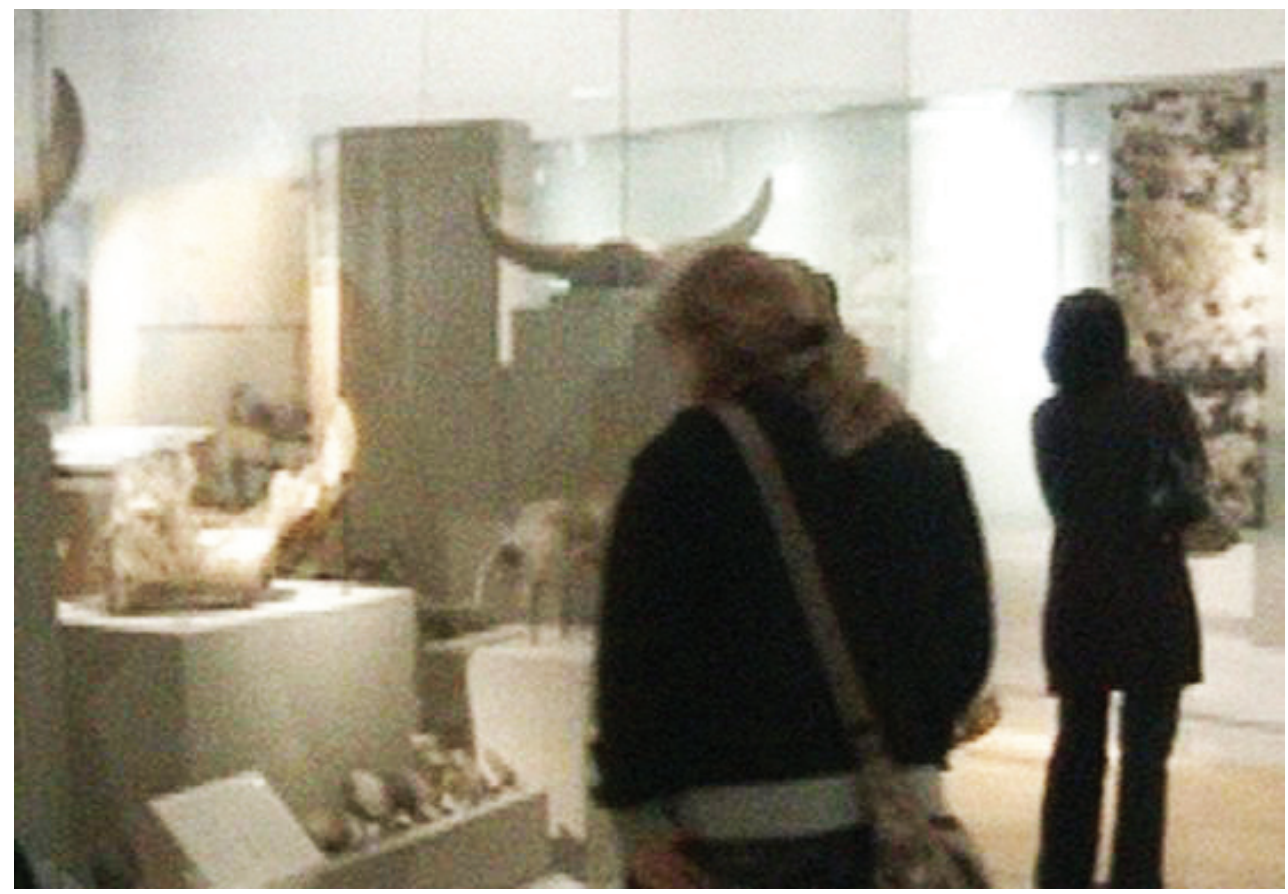

Figure 9 
W2 with the slight distancing and overview of the performance of W1 is a marker of a clear framing of the space and possibly a performative action of one who has a sense of ownership of what has been framed (Figure 9).

This excerpt illustrates how within just a few seconds two differently embodied instances may succeed each other; each of the visitors takes the lead through multimodal agentive actions, inviting the other to engage with the selections and framings they have made. Each one of the visitors here has initiated their performative action through modes beyond the linguistic and through different articulations and assemblages of the modes of gaze, gesture and movement. Every assemblage of modes and orchestration at each given moment is a marker of the meaning-maker's interest and the meaning-makers' engagement with that aspect of the exhibition.

It is the particular resources that each mode comprises that are aptly used by the visitors to perform their engagement and actively design the museum experience for themselves and their companions. The term 'resources comprising each mode' refers, in the instance of movement for example, to the orientation of body parts, pacing, rotation, proximity, distance, angle and point of view, which have been selected by each of the two visitors in the process of directing the attention of their companion. These are some of the resources used in the multimodal performance they conduct, while at the same time seeing the exhibition and their companion's equivalent communicative act. The movement of the visitors in this instance forms a prompt and an invitation for engagement in museum spectatorship. Movement is a means of framing the visiting experience and in this particular instance has taken the lead mode that has shaped the orchestration of all the other modes.

\section{Negotiating co-presence on the museum floor}

The following excerpt from our Wellcome Collection research involves one group comprising a female adult (W1) and two female children (D1 and D2) who follow the museum's activity pack available for families. The observation starts when the group is half way through their gallery exploration, and follows D1 who has taken the lead as she holds the activity leaflet. This excerpt is indicative of the use of modes of communication that visitors draw upon in order to (i) regulate their co-spectatorship when members of the same group disperse and re-join, and (ii) monitor, regulate, and negotiate their co-spectatorship when encountering strangers.

D1 approaches the painting section and positions herself in close proximity to it. Her body, footing and gaze are directed to the paintings mounted on the top left side of the wall. D1 glances at the leaflet she holds - a shift in her head's position and gaze embody her active participation in the family trail. Her performance is considered an embodied animation of her interest and active participation in locating the exhibit that provides the focus of their next activity (Figure 10). Her positioning and glancing at the paintings section are complimentary to her glances at the leaflet she holds. Positioning and glancing are instances of an embodiment of her attempt to confirm that the exhibit she has just located is the one identified in the family trail leaflet.

Once assured that she has found the exhibit, she turns her head to the left towards W1 and D2 (Figure 11). The shift in posture, realized through the turn of her head and redirection of her gazing to the left, is an embodied performance of her shift in attention and her interest in making her discovery public. Specifically, turning around allows D1 to scan the gallery space quickly and monitor the co-presence of her group, locating them in the gallery space. By doing so, D1 prepares the ground for her next performance. Meanwhile, W2, a bystander, has also approached the painting section from the left. W2 can be seen picking up a leaflet, and starting to walk, moving from left to right. The presence and close proximity of another visitor who has no previous connection to the performer (D1) is of great importance for what unfolds next.

According to Goffman (1963; 1981), during the staging of one's self there can be three roles: (1) the performer, (2) the spectator(s), who represents the audience and (3) the bystanders or overhearers, that is, any individual present who has not been acknowledged as a ratified member of the interaction. All three roles in any given encounter form a 'participation framework' of which the performer, spectator and bystander are members (Goffman 1981: 226). Those who just happen to be in the same spatial and temporal context are part of the 


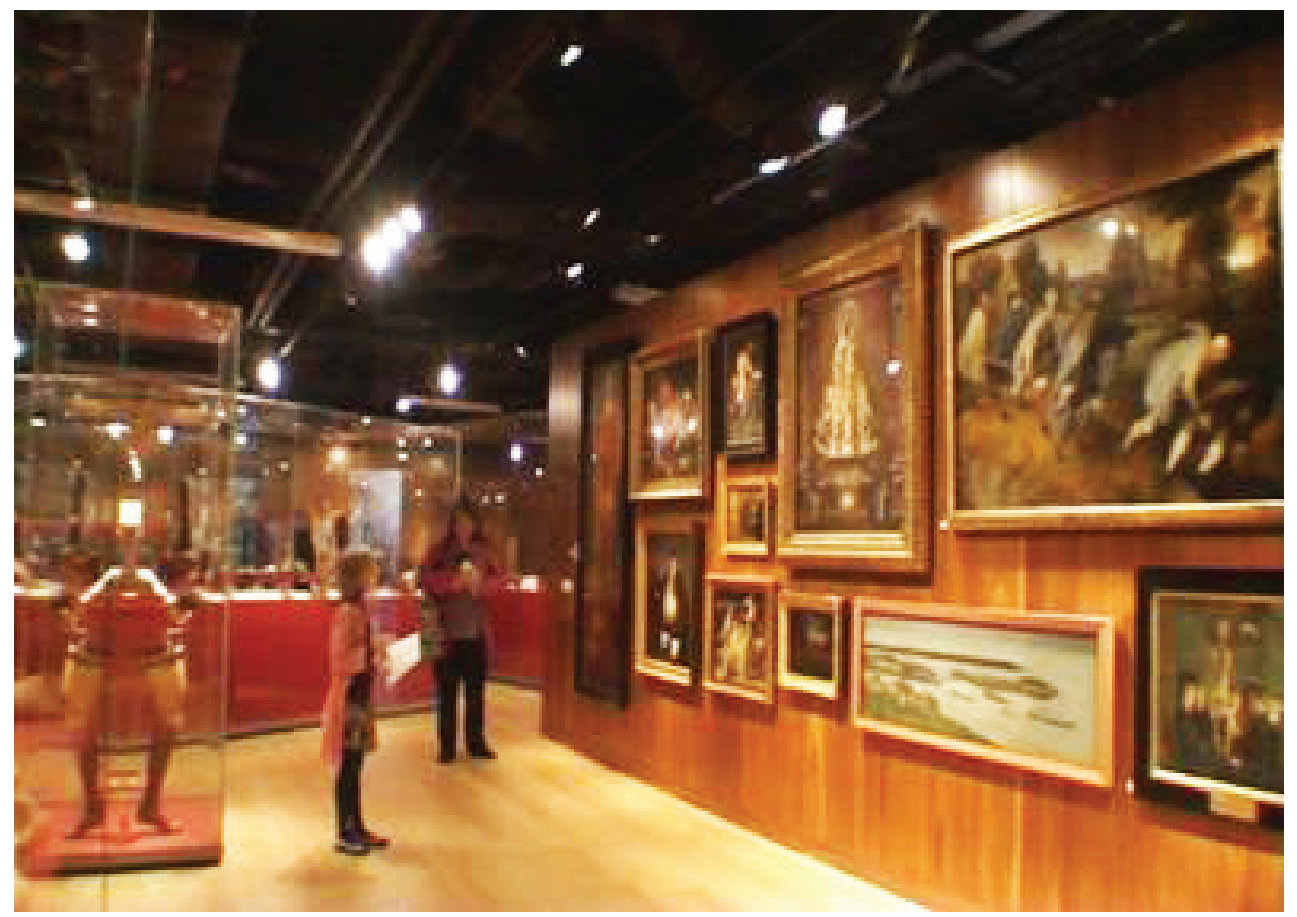

Figure 10

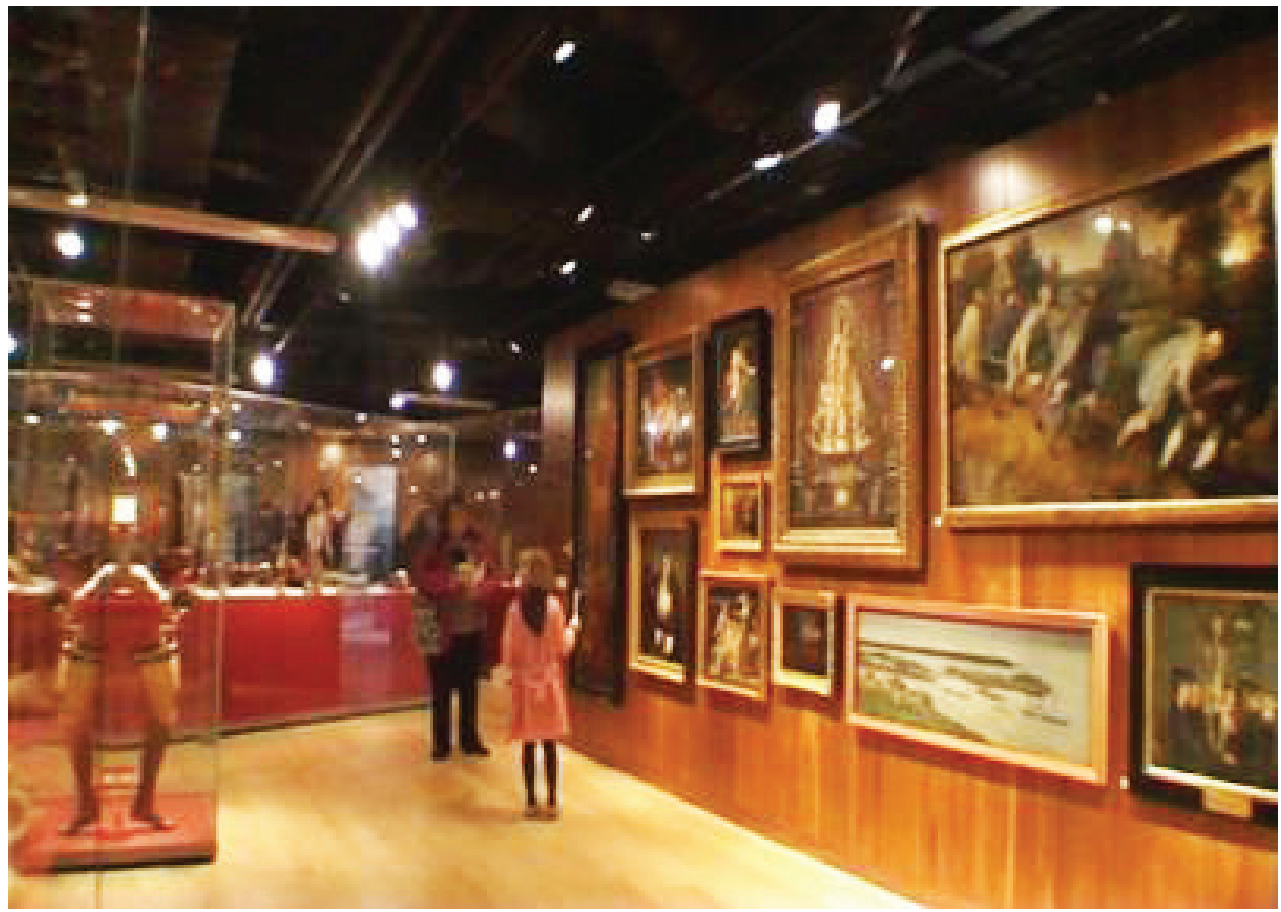

Figure 11 


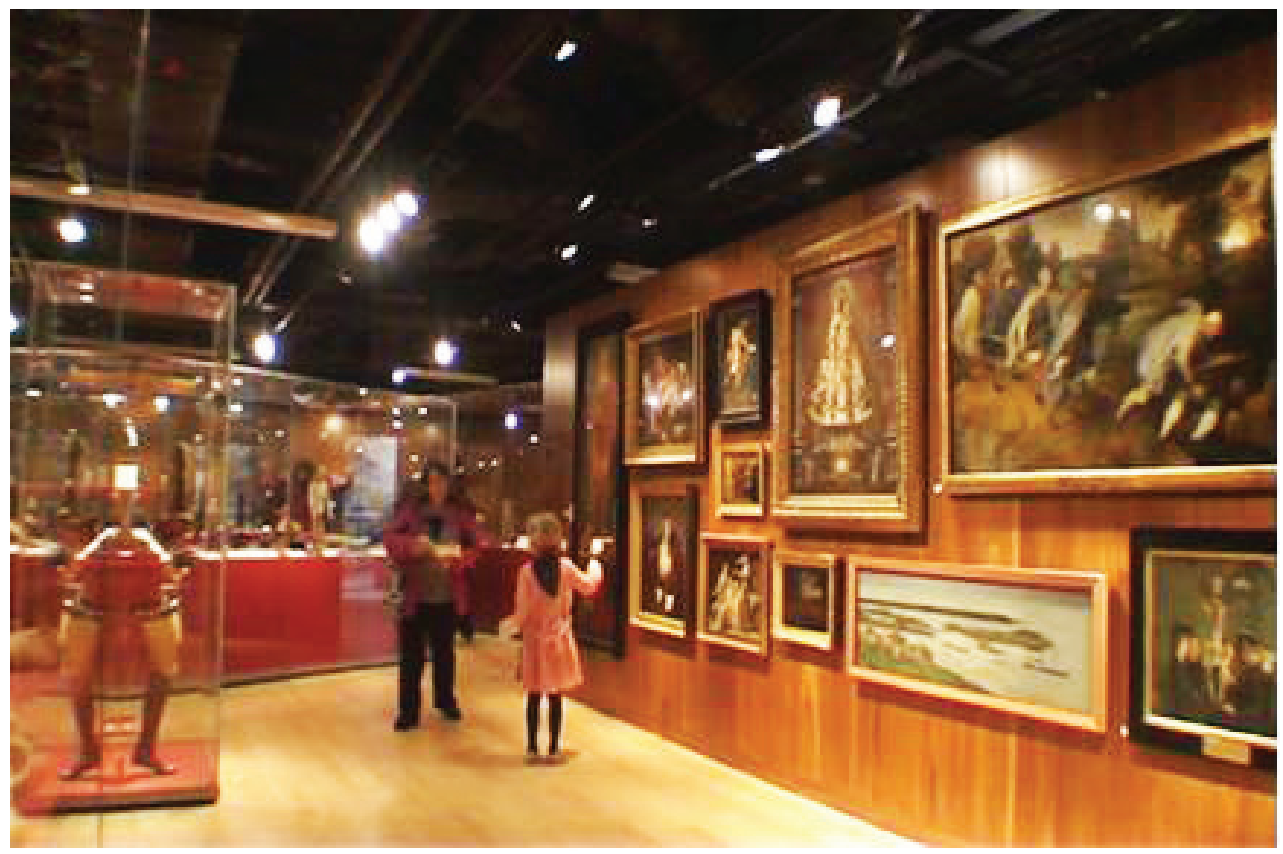

Figure 12

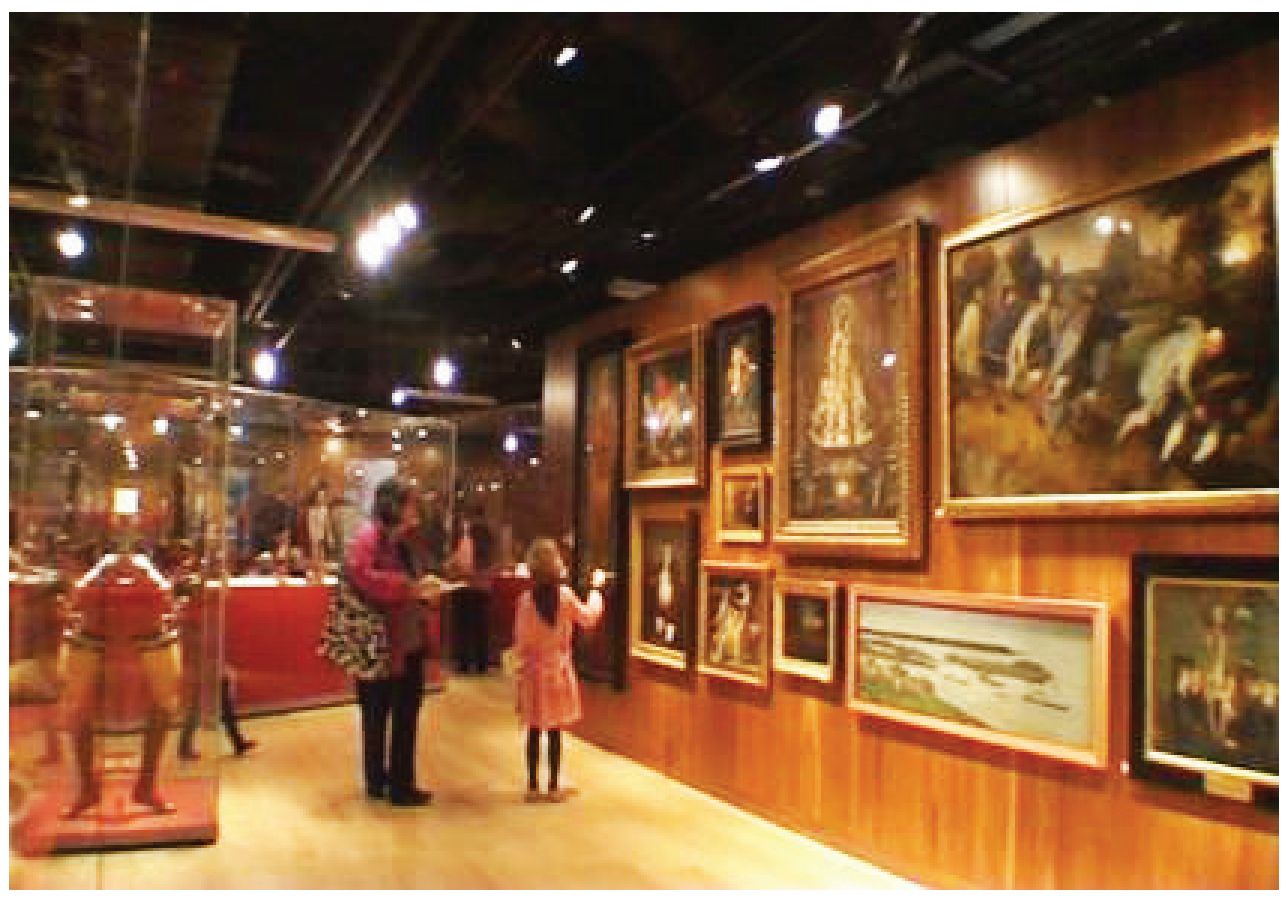

Figure 13 


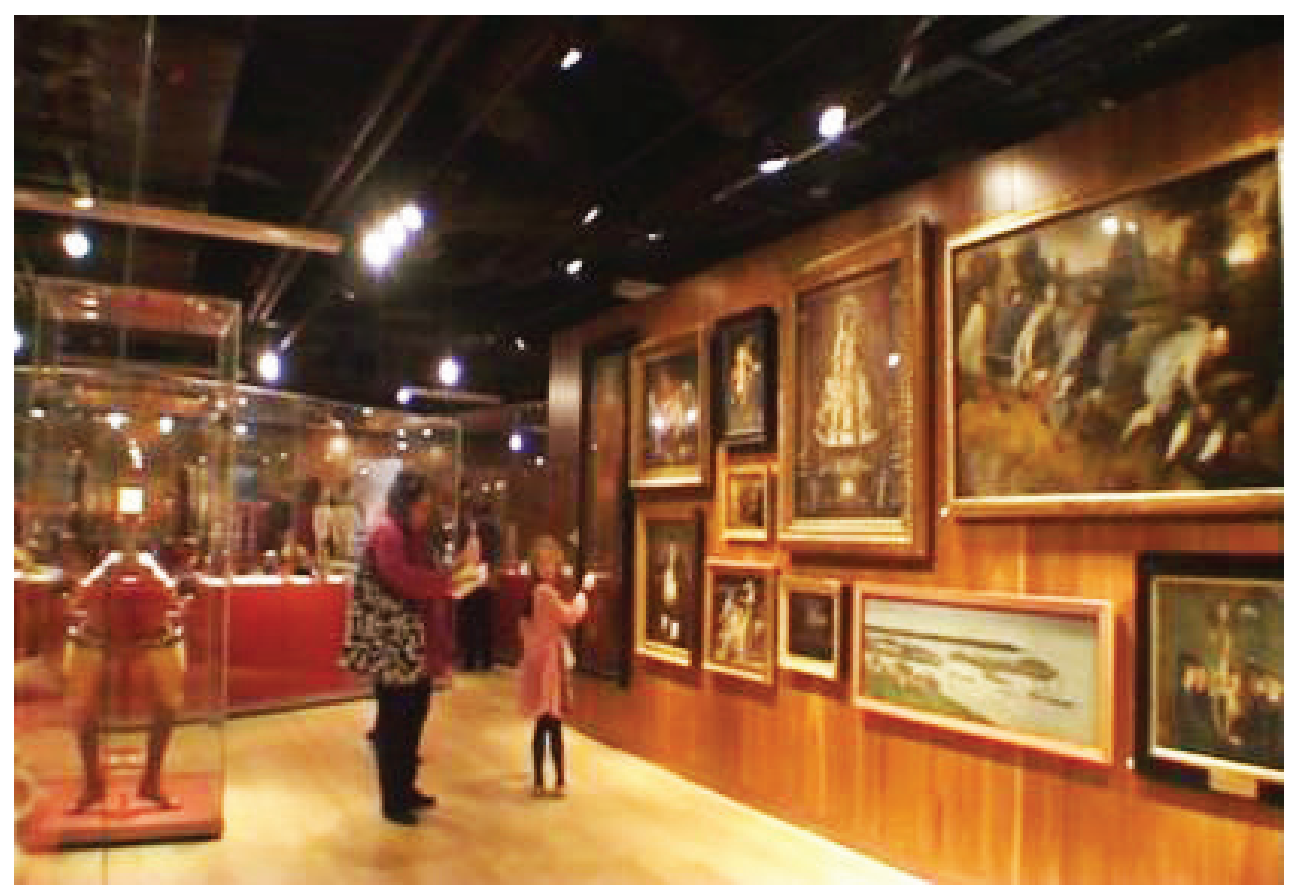

Figure 14

'perceptual range' of the event (Goffman 1981: 3). Therefore, the adult who just happened to be close to D1 is a bystander, who is in the perceptual range of her experience.

As W1 and D2 are still at a distance, D1 draws upon an alternative means in order to identify the audience of her performance: she uses person-reference by saying, 'mommy'. Person-reference is a verbal category that carries out the identification of the person being summoned (Schegloff 2007) - in this case D1 uses the kin title 'mommy' to refer to W1. Kin titles overtly tie the referent to a specific individual and its use may be seen in the light of the bystander's presence. D1 tags verbally those whom she wants to include in her encounter, while excluding others who happen to be around (W2). Through this person-reference, D1 attempts to attract her addressee's attention and thus regulate their distance and regain proximity.

Followed by a quick lift of her right hand pointing at the painting with the pencil she holds, D1 resumes her initial performance. She again faces the painting with her whole body, while now also lifting her right hand pointing at the specific painting under request in the family trail leaflet. While facing and pointing at the painting, D1 turns to her left to where the rest of her fellow visitors stand (Figure 12). With her gaze D1 monitors her fellow visitors while pointing her hand at the painting for seven seconds. By orchestrating all these modes (pointing, shifts in body posture, and shifts in gaze), D1 attempts to triangulate between herself, her addressees and the referent object, the painting. Moreover, the elaborated duration of her pointing gesture and shift in gaze can be seen as her effort and interest to hold the ground for the two fellow members of her group, so that they can pay attention to her performances and discovery. It can therefore be considered a means for motivating them to move on and resume close proximity to her.

Meanwhile, W2 walks towards D1, and stands right behind her, shifting her gaze from the painting section to the leaflet she holds and vice versa (Figure 13). These performances may indicate W2's focus on her own spectatorship while still being tuned into the presence of other visitors close by. Within this social situation, proximity and orientation are of crucial importance as participants orient themselves to others in order to include them in the ongoing encounter, whereas they position themselves away from those who happen to be present without officially participating in the ongoing encounter. Goffman (1964) also suggests that 
the exclusion of those who are not ratified members of the encounter is further achieved by a regulated sound level and physical orientation that shows respect to those excluded. We have argued earlier in this article that visitors often adopt 'involvement shields' (Goffman 1963: 38) to avoid social interaction with others. We consider the bystander's shift in gaze and controlled route and pace around D1 among these 'involvement shields' adopted by visitors in the course of their encounters with strangers.

Additionally, D1 does not leave her performance space which she prepares carefully aiming to form an 'ecology of participation'. According to Heath and his colleagues (Heath et al. 2002: 23) 'the conduct of others within the same space can feature in and influence how people orient themselves, what people choose to look at and how they experience particular objects, artefacts and events'. This ecology of participation hints at the ways in which an exhibit is not only shaped by visitors' perceptions and cognition but also through social interaction. This example shows that encountering an exhibit is an intrinsically social activity as the visitor is continually responsive to the conduct of others in the immediate environment. It further hints at the twofold ways in which co-presence may impact on a particular experience both as a resource and a constraint. Visitors draw upon co-presence as a resource informing their interpretation and meaning making while also informing their own conduct, configuring their conduct in space moment-by-moment (Christidou 2015).

D1 does not remain aloof to the bystander (W2); instead she turns to her right and looks towards W2 (Figure 14). Through her turn, apart from acknowledging the unratified member in her forthcoming ecology of participation, she attempts to 'monitor co-presence' (Gahagan 1984). This monitoring behaviour allows interacting participants to monitor those who are present and possibly to adjust their behaviours accordingly while still sustaining the interaction with the ratified members of their group (Goffman 1963). Visitors are 'performatively attuned to the spectacle of the performance of others' (Bagnall 2003: 95) This sheds light on how visitors invite others into an encounter while keeping others at an arm's length.

This example affords better understanding of how museum visitors' actions are the result of agency (or even agencies) which emerges in a particular context and is regulated and negotiated amongst other participating actors, or by those simply present, in an unfolding network.

\section{Discussion}

This article draws upon both established and recent developments in sociology, envisioning museum galleries as theatrical stages, with visitors enacting scripted or improvised embodied performances by shifting between the social and individual aspect of their visit. In the light of this performativity, museum spectatorship becomes more than 'seeing' and 'being seen' - it gains multimodal dimensions which are inextricably linked to visitors' bodies as they move through the galleries, making constant selections in and through social interaction. The fragments analyzed highlight the sensitivity of visitors to the presence of others, fostering as such an understanding of the museum experience as a 'choreography' (Diamantopoulou and Christidou in press).

The two aforementioned examples have illustrated (i) the richness of embodied practices performed during museum spectatorship, (ii) the twofold nature of these practices as context sensitive and context renewing and generating, as these are informed by what unfolds, while also informing what happens next in the galleries moment-by-moment, and (iii) the ways in which these practices, coupled with talk, are part of visitors' agency. Hopefully, what the two examples have established is that, while the artwork remains relatively static, visitors design a temporal experience of it by moving through, in and out of the gallery space. The relevance of the artwork does not stem from the artwork itself and its inherent artistic qualities, but from the visitors' engagement with it. Previously, museum encounters were perceived as bound temporally to the viewer by the time spent in front of the artwork. On the contrary, this article has argued that all museum encounters unfold on the museum floor and at the same time coalesce into a choreographed performance in which visitors rely on others' verbal and embodied conduct, displaying to each other momentarily their understanding of what they are doing, what they are intending to do and what is going on. 
This article addresses the need for interdisciplinary approaches in the field of museum studies by drawing upon the theories of multimodality and ethnomethodology. It suggests that each theoretical approach could potentially be methodologically and interpretatively enriched by the other, and thus, it synthesizes these different approaches by discussing them in two specific contexts. The examples used, although drawn from two different projects that adopted slightly different epistemologies and methodologies, facilitate understanding of how visitors employ a range of different modes of communication during their engagement with the exhibits, and how these modes are used to regulate their ongoing engagement with their co-visitors (Christidou 2015).

This article has paid particular attention to how visitors may use their bodies to block access to an exhibit, and how they have used their gaze, footing, and pointing to monitor copresence around it. The alternate shifts between modes ascribe a sense of 'dancing', with visitors performing as 'dancers of agency' (Diamantopoulou and Christidou in press). The approach adopted in this article moves away from previous research that has investigated visitors' bodies while in the galleries so as to determine the effectiveness of exhibition design and measure the 'attracting' and 'holding' power of exhibits (Bitgood 2006 2014) or examine the ways in which specific exhibit features prompt particular behaviours (Allen 2002).

By questioning the underlying assumption that all movement unfolds in response to the design of exhibitions, this article aims to foreground visitors' agency in the shaping of their encounters. The main thrust in this article is to demonstrate the importance of employing an analytical and interpretative framework which allows exploration of the museum experience by attending to the significance of movement, gaze and pointing gestures, which are often seen as subordinate to speech. It is important that the supremacy of linguistically realised utterances of visitors through speech and writing are questioned to help unlock the full spectrum of their engagement with the exhibition and the social context through a range of communicative modes. Documenting the ways in which people use and engage with museum collections allows a greater understanding of the ways in which these are experienced. Such documenting can also be used to explore the ways in which visitors connect with each other and the collection as they 'see' the exhibits and other co-present visitors, while in return being seen by those happening to share the same space at the same time.

Received $3^{\text {rd }}$ March 2015

Finally accepted $10^{\text {th }}$ December 2015

\section{Note}

1 The two projects are: (a) the international project 'The museum, the exhibition and the visitor: Learning in the new arena of communication', funded by the Swedish Research Council (2007-2010), and (b) Christidou's doctoral project, funded by the Greek Scholarships Foundation, (2008 - 2012) and covered by the UCL Data Protection Registration; reference No Z6364106/2009/11/30, Section 19, Research: Social Research.

\section{References}

Allen, S. (2002) 'Looking for learning in Visitor Talk: A Methodological Exploration' in Gaea Leinhardt, Kevin Crowley, and Karen Knutson (eds) Learning conversations in museums, 259-303, Mahwah, NJ: Lawrence Erlbaum.

Bagnall, G. (2003) 'Performance and Performativity at Heritage Sites', Museum and Society, 1 (2) 87-103.

Bennett, T. (1994) The Birth of the Museum: History, Theory, Politics, London: Routledge.

Bezemer, J. and Mavers, D. (2011) 'Multimodal Transcription as Academic Practice: A Social Semiotic Perspective', International Journal of Social Research Methodology, 14 (3) 191-207. 
Bitgood, S. (2014) Engaging the Visitor: Designing Exhibits that Work, Edinburgh: MuseumsEtc.

Bitgood, S. (2006) 'An Analysis of Visitor Circulation: Movement Patterns and the general value principle', Curator, 49 (4) 463-75.

Borden, I. (2001) 'Another Pavement, another beach: Skateboarding and the performative critique of architecture', in lain Borden, Joe Kerr, and Jane, Rendell (eds) The Unknown City: Contesting Architecture and Social Space, 178-99, Massachusetts: MIT Press.

Christidou, D. (in press) 'Social Interaction in the Art Museum: Performing etiquette while connecting to each other and the exhibits' The International Journal of Social, Political, and Community Agendas in the Arts, [volume and issue tbc]

(2015) 'Isolating the Private from the Public: Accounting for Co-Presence in the Museum', IIEMCA Conference 2015 - Living the material world, The International Institute for Ethnomethodology and Conversation Analysis - Kolding, Denmark 4-7 August 2015.

(2013) 'Bringing Meaning into Making: How Do Visitors Tag an Exhibit as Social when Visiting a Museum', The International Journal of the Inclusive Museum, 6 (1), 73-85.

(2012) 'Does "pointing at" in Museum exhibitions make a point? A Study of Visitors' Performances in Three Museums for the Use of Reference as a Means of Initiating and Prompting Meaning-making', Unpublished PhD thesis, University College of London.

Davies, M. and Heath, C. (2014) "'Good" Organisational Reasons for "Ineffectual" Research: Evaluating Summative Evaluation of Museums and Galleries', Cultural Trends, 23 (1) 57-69.

Deeth, J. (2012) 'Engaging Strangeness in the Art Museum: an audience development strategy' Museum and Society, 10 (1) 1-14.

Diamantopoulou, S. (2008a) 'Designs for learning in Museums: The Roman and Prehistoric galleries at the Museum of London as multimodally and discursively constructed sites' Paper presented at the Designs for Learning Conference, Institute of Education, Stockholm University, 3-4 March 2008.

Diamantopoulou, S. (2008b) 'Learning on archaeological sites: A multimodal social semiotic approach' Hermes: Journal of Language and Communication Studies, 41, 81-105.

Diamantopoulou, S. \& Christidou, D. (in press) 'The Choreography of the Museum Experience: Visitors' Designs for Learning' The International Journal of Arts Education [volume and issue tbc].

Diamantopoulou, S., Insulander, E. and Lindstrand, F. (2012) 'Making Meaning in an Exhibition: Technologies, Agency and (re-)Design' Designs for Learning Journal, 5 (1-2), 11-29.

Diamantopoulou, S. and Kress, G. (forthcoming) 'Designs and Signs of Learning at the Museum: A Multimodal Social Semiotic Approach to a Visitor Study' [working paper]

Diamantopoulou, S. and Kress, G. (2010) 'Movement and Space', Pre-conference Multimodal Analysis Master Class, Multimodality and Learning Conference, Institute of Education (5 July 2010). 
Dicks, B. (2014) 'Action, experience, communication: three methodological paradigms for researching multimodal and multisensory settings' Qualitative Research, 14 (6), 65674.

Duncan, C. (1995) Civilizing Rituals: Inside Public Art Museums, London: Routledge.

Duranti, A. (2004) 'Agency in Language' in Alessandro Duranti (ed.) A Companion to Linguistic Anthropology, 451-73, Malden, Mass: Blackwell.

Gahagan, J. (1984) Social Interaction and Its Management, New York: Methuen.

Garfinkel, H. (1967) Studies in Ethnomethodology, NY: Prentice Hall.

Goffman, E. (1963) Behavior in Public Places: Notes on the Social Organization of Gatherings, New York: The Free Press.

Goffman, E. (1964) 'The Neglected Situation', American Anthropologist, 66 (6) 133-6.

Goffman, E. (1971) Relations in Public: Micro-Studies of the Public Order, New York: Basic Books.

Goffman, E. (1981) Forms of Talk, Philadelphia: University of Pennsylvania.

Gutwill, J. (2002) 'Gaining Visitor Consent for Research: Testing the Posted-Sign Method', Curator: The Museum Journal, 45 (3) 232-8.

Heath, C., Luff, P., Vom Lehn, D., Hindmarsh, J., Cleverly, J. (2002) 'Crafting Participation: Designing Ecologies, Configuring Experience', Visual Communication, 1 (1) 9-33.

Heritage, J. (2008) 'Conversation Analysis as Social Theory' in Bryan, Turner (ed.) The New Blackwell Companion to Social Theory, 300-20, Oxford, UK: Blackwell.

Heritage, J. (1984) Garfinkel and Ethnomethodology, Oxford: Blackwell.

Illeris, H. (2006) 'Museums and galleries as performative sites for lifelong learning', Museum and Society, 4 (1) 15-26.

Ingold, T. (2011) Being Alive: Essays on Movement, Knowledge and Description, London: Routledge.

Insulander, E. (2010) Tinget, rummet, besökaren Om meningsskapande på museum, Stockholm: Stockholms universitets förlag.

Knutson, K. and Crowley. K. (2010) 'Connecting with Art: How Families Talk about Art in a Museum Setting', in Mary Kay, Stein and Linda, Kucan (eds) Instructional Explanations in the Disciplines, 189-206, New York: Springer.

Kress, G. (2010) Multimodality: A Social Semiotic Approach to Contemporary Communication, London: Routledge.

Leinhardt, G., Crowley, K. and Knutson, K. (eds) (2002) Learning Conversations in Museums, Mahwah, NJ: Lawrence Erlbaum Associates.

Leinhardt, G. and Knutson, K. (2004) Listening in on Museum Conversations, Walnut Creek, CA: Altamira Press.

Leahy, H. (2012) Museum Bodies: The Politics and Practices of Visiting and Viewing, Farnham: Ashgate. 
Lindstrand, F. (2008) 'Sediments of Meaning - Signs, Design and Meaning-making at the museum'. Paper presented at the 1st international conference Designs for learning: Defining the field, 3-4 March, Stockholm University.

McClellan, A. (2003) 'A Brief History of the Art Museum Public' in Andrew McClellan (ed) Art and Its Publics: Museum Studies at the Millennium, Blackwell: Oxford.

Macleod, S., Hanks, L., and Hale, J. (2012) Reshaping Museum Space: Architecture, Design, Exhibitions, Routledge: London.

O'Neill, M.C., and Dufresne-Tasse, C. (1997) 'Looking in everyday life/Gazing in museums', Museum Management and Curatorship, 16 (2), 131-42.

Pattison, S. A. and Dierking, L. D (2013) 'Staff-mediated Learning in Museums: A social interaction perspective', Visitor Studies, 16 (2) 117-43.

Pickering, A. (1995) The Mangle of Practice: Time, Agency and Science, Chicago: University of Chicago Press.

Pierroux, P. (2003) 'Communicating Art in Museums: Language Concepts in Art Education', Journal of Museum Education, 28 (1) 3-8.

Pink, S. (2010) 'The Future of Sensory Anthropology/the Anthropology of the Senses' Social Anthropology, 18 (3) 331-33.

Roppola, T. (2013) Designing for the Museum Visitor Experience, London: Routledge.

Rowe, S. (2002) 'The role of Objects in Active, Distributed Meaning-making' in Scott, Paris (ed.) Perspectives on Object-centered Learning in Museums, 19-36, Mahwah NJ: Lawrence.

Schegloff, E. (2007) 'Categories in Action: Person-reference and Membership Categorization', Discourse Studies, 9 (4), 433-61.

Tzortzi, K. (2014) 'Movement in Museums: Mediating between Museum Intent and Visitor Experience', Museum Management and Curatorship, 29 (4) 327-48.

vom Lehn, D. (2013) 'Withdrawing from Exhibits: The Interactional Organisation of museum visits', in Pentti, Haddington, Lorenza, Mondada and Maurice, Nevile (eds) Interaction and Mobility: Language and the Body in Motion, 65-90, Berlin: De Gruyter.

(2008) 'Examining "Response": Video-based Studies in Museums and Galleries', International Journal of Culture, Tourism and Hospitality Research, 4(1) 33-43.

(2002) Exhibiting Interaction: Conduct and Participation in Museums and Galleries. London: Unpublished PhD thesis, King's College, University of London.

vom Lehn, D. and Heath, C. (2007) 'Social Interaction in Museums and Galleries: A Note on Video-Based Field Studies', in Ricki, Goldman, Roy, Pea, Brigid, Barron, and Sharon, Derry (eds) Video Research in the Learning Sciences, 287-301, Mahwah, $\mathrm{NJ}$ : Lawrence Earlbaum Associates.

vom Lehn, D., Heath, C., and Hindmarsh, J. (2001) 'Exhibiting interaction: Conduct and collaboration in museums and galleries', Symbolic Interaction, 24(2) 189-216.

Yalowitz. S. and Bronnenkant, K. (2009) 'Timing and Tracking: Unlocking Visitor Behavior', Visitor Studies, 12(1) 47-64. 
${ }^{*}$ Dr Dimitra Christidou works as a researcher and project manager at the Nordic Centre of Heritage Learning and Creativity (NCK), a Nordic Baltic centre for learning through cultural heritage, located in Östersund, Sweden. Dimitra holds a PhD in Museum Studies from the University College of London, funded by the Greek State Scholarships Foundation (I.K.Y.). Her thesis explored visitors' social interaction in the galleries. Dimitra is interested in, among others, evaluation, visitor studies, issues of identity, and meaning making in museums.

Address:

The Nordic Centre of Heritage Learning and Creativity AB,

Box 709 ,

83128 Östersund,

Sweden

Tel: (+46) 0735520271

Email: christidou.dimitra@gmail.com

**Sophia Diamantopoulou is a freelance researcher in Museum and Art Gallery Education in the UK. She is a member of the Centre for Multimodal Research at the Institute of Education, University College London (UCL), where she has previously worked for twelve years, on various national and international projects, including collaborations with Tate Britain and the National Gallery. Sophia holds an MA in Museum Studies from University College London. She is interested in multimodal social semiotic and discourse analytic approaches to learning in museums and exhibition design. Sophia is currently completing her $\mathrm{PhD}$ on multimodal perspectives of learning in museums.

Address:

20 Bedford Way,

London WC1H OAL,

United Kingdom

Tel: (+44) 07946321347

Email: s.i.diamantopoulou@gmail.com 